\title{
Welfare Workers' Responses to Domestic Violence Cases: The Effects of Training and Worker Characteristics
}

\author{
Daniel G. Saunders, Mark C. Holter, Lisa C. Pahl, \& \\ Richard M. Tolman
}

\begin{abstract}
This study evaluated a one-day domestic violence training for Temporary Assistance for Needy Families (TANF) workers and analyzed the relationship between worker characteristics and the use of work exemptions. In a post-only evaluation, trained workers reported a greater tendency than untrained workers to refer clients to couples counseling, make a safety plan, and file a report to child protection services. In a pre/post evaluation, workers reported after training that they would be less likely to refer clients to couples counseling, and more likely to ask about the emotional and physical impact of abuse, make a safety plan, and ask about access to weapons. Workers most likely to offer a waiver from work requirements reported a higher likelihood of making referrals for a variety of services.
\end{abstract}

A number of concerns have surfaced recently regarding the response of welfare workers to instances of domestic violence. Evidence indicates that domestic violence is present in a high percentage of cases, yet is usually undetected. In addition, policies that require work or work training might place victims in more danger. Lifetime rates of domestic violence among women on welfare range from $34 \%$ to $65 \%$ (GAO, 1998; Tolman \& Raphael, 2000), and most studies find rates between $20 \%$ and $30 \%$ for recent abuse (GAO, 1998; Lyon, 2002; Tolman \& Raphael, 2000). A national policy shift has also heightened concerns. With the passage of the Personal Responsibility and Work Opportunity Reconciliation Act (PRWORA) in 1996, welfare as a cash entitlement program for families living in poverty ended and was replaced with Temporary Assistance to Needy Families (TANF). The Act sets strict work requirements for maintaining benefits, with a benefit limit of two consecutive years, and a five-year lifetime limit.
New requirements may keep survivors in abusive relationships because domestic violence can interfere with employment and might subsequently reduce benefit compliance. Economic resources are often necessary to helping women leave and remain out of abusive relationships (Anderson \& Saunders, 2003; Rhodes \& McKenzie, 1998). These resources can take the form of monetary incentives for welfare recipients to obtain work and in one experiment such incentives were related to higher employment and lower rates of domestic violence (Gennetian, 2003). Work or work training can become difficult because many women are harassed, stalked, abused, and intimidated by their ex-partners (GAO, 1998; Lyon, 2002; Moore \& Selkowe, 1999; Sable et al., 1999; Romero, Chavkin, Wise, \& Smith, 2003; Staggs \& Riger, 2005; Swanberg \& Logan, 2005). Abuse can also interfere with employment indirectly due to depression, anxiety disorders, substance abuse, and other psychological problems experienced by 
survivors (Brush, 2000; GAO, 1998; Tolman \& Raphael, 2000; Tolman \& Rosen, 2001). Such emotional problems can interfere with work and work training (CIMHCalWORKS, 2002a; Meisel, Chandler \& Rienzi, 2003) and thus battered women risk losing their work and their benefits (Moore \& Selkowe, 1999). Many believe that rigid work requirements may lead to an escalation of abuse because many offenders feel threatened by their partners' independence (Raphael, 2000) and there is some evidence that work aggravates abuse (Brush, 2003). ${ }^{1}$ Due to the above concerns, the Family Violence Option (FVO), adopted as an amendment to PRWORA, allows states the option of temporarily waiving federal work requirements for renewable six month periods when domestic violence is a barrier to meeting requirements (Raphael, 1999). ${ }^{2}$

The economic and physical risks to adult victims and their children can increase when domestic violence goes undetected. Once abuse is detected, caseworkers need to know how to respond properly. These responses can include referrals, work requirement waivers, and brief interventions (Davies, 1998a) and can lead to increased safety for battered women and their children. Increasingly, research is providing information on rates of victim disclosure, reasons for nondisclosure, and the response of caseworkers.

\section{Adoption of Work Requirement Waivers}

By the year 2005, 48 states had adopted the FVO, along with similar policies of their own (ACF, 2002; GAO, 2005; Legal Momentum, 2004; Raphael, 1999; Sachs, 2000). ${ }^{3}$ Written verification of the abuse is required or a written affidavit from the victim (Raphael, 1999). Applicants for aid in some states are informed verbally or in writing about the problem of domestic violence and why disclosure might be useful. Most states use or plan to use a special formal assessment instrument to aid detection. The level of detail of these instruments varies widely, with some being a single line prompt (GAO, 2005).

Michigan, where this study was conducted, adopted its own version of the FVO. Legislation taking effect in October 1998 mandated that the Family Independence Agency (FIA) "screen and identify individuals... who have a history of domestic violence," (p. 102); refer those individuals to counseling and supportive services; and

\footnotetext{
1 Work may also lower symptoms of PTSD (Brush, 2003).

2 Policies have also been developed nationally and in particular states to grant exemptions from stipulations requiring child support enforcement if doing so would place a victim in danger (Pearson, Griswold, \& Thoennes, 2001).

3 The FVO was not wholeheartedly endorsed by all victim advocates. Some feared that disclosure would mean that all cases would be reported to the child protection unit because the mother would be held responsible for exposing the children to abuse, that the abuser might retaliate, or that overgeneralizations about the traits of battered women would make workers think that victims could not work and thus did not need any assistance (Davies, 1996).
}

waive program requirements if compliance would make it more difficult to escape domestic violence, would penalize victims, or an individual was at risk of further domestic violence (State of Michigan, Act No. 162, 1997). FIA policies adopted by Michigan in January 1999 allowed a waiver of work requirements for three months, which is renewable with supervisory approval. Clients were notified of the work requirement waiver during a work program orientation. In October 2000 a brochure was made available to clients that described signs of domestic abuse, exemptions to work and child support requirements, and sources of help. Caseworkers in Michigan in 2002 rarely listed domestic violence as the reason for deferral from the work program, accounting for approximately $1 \%$ of all deferrals and $.005 \%$ of all cases.

\section{Disclosure Rates}

Rates of domestic abuse disclosure in general have been extremely low, ranging from $1 \%$ to $4 \%$ in states with the FVO (Hagen \& Owens-Manley, 2002; Raphael, 1999). Surprisingly, detection rates were also very low-less than one percent-even when a domestic violence specialist was available (Lein, Jacquet, Lewis, Cole, \& Williams, 2001). Detection rates were found to be much higher (13$21 \%)$ in some states with many years of experience using intensive case management.

\section{Caseworker and Agency Variables}

The response of welfare workers to battered women might be explained by their general work orientation. For example, many of them are not prepared to encounter the complex assessment, case management, and support roles needed for domestic violence cases, but rather were trained to give income support (GAO, 2005; Hagen \& Owens-Manley, 2002; Levin, 2001). Most states require little or no training on domestic violence screening for caseworkers or intake workers (GAO, 2005). Client focus groups in Michigan found that clients strongly desired that staff improve their attitudes (Rossman \& Associates, 1999). At times, worker discomfort in trying to listen nonjudgmentally to traumatic incidents may turn to hostility (Levin, 2001) and a tendency to pass judgment on clients (Postmus, 2002). They may have difficulty understanding why many women return to abusive partners (Hagen \& Owens-Manley, 2002) and are more likely to grant waivers if women showed initiative, such as going to a shelter or obtaining a restraining order. A small proportion of workers appear to believe that some clients lied about being victims in order to receive special services (Brush, 1999; Hagen \& Owens-Manley, 2002).

The attitudes of workers could lead to ineffective actions once abuse is detected. Only a fourth of the welfare recipients identified as battered women in a Wisconsin study 
were referred for counseling (Moore \& Selkowe, 1999). Less than $10 \%$ were told that part of their work activities could include getting help for abuse (Moore \& Selkowe, 1999). ${ }^{4}$ In two California counties, only about half of the seriously abused women reported receiving help from a professional (CIMH-CalWORKS, 2002b). In a study of 10 battered women in a state with the FVO, none of them were asked directly about abuse and none received the services to which they were entitled; there were indications that workers' discretionary behavior focused more on reducing caseloads than on providing violence-related services (Lindhorst \& Padgett, 2005). A study of employment training for staff showed that most of them did not recognize the risk markers for domestic violence (Brush, 1999).

There is some indication from a study of child support workers that much higher abuse disclosure rates can be attained with direct questioning than with distribution of a brochure or other indirect methods (Griswold, Pearson, \& Thoennes, 2000; Pearson, Griswold, \& Thoennes, 2001). The majority of clients agreed that it was best for workers to ask everyone about domestic violence. Many of these clients, as with welfare clients, did not have serious or recent abuse and did not want a waiver from the rules; rather, they wanted the child support collection to occur (see also Pearson, Thoennes, \& Griswold, 1999). Child care and transportation were mentioned much more often than domestic violence as barriers to meeting TANF requirements, similar to studies in other welfare settings (Lein et al., 2001; Sable, Libbus, Huneke \& Anger, 1999; Saunders, Ward, \& Dow, 1999). In addition, health and emotional problems were mentioned as barriers by less than $20 \%$ of the women (Pearson, Griswold, \& Thoennes, 2001).

One review found that four to five times as many clients were willing to disclose domestic violence to a domestic violence advocate than to a caseworker (Raphael \& Haennicke, 1999). These advocates were staff from local programs or in-house experts who became specialized caseworkers or domestic violence "point person[s]" (Burt, Zweig, \& Schlichter, 2000). Domestic violence counselors can also be present at employment service agencies and provide counseling, crisis intervention, safety planning, support groups, legal advocacy, and referrals (McKean, 2004). Counselors at several sites helped determine if a waiver was appropriate and their services were viewed as helpful by recipients. Several states employ domestic violence counselors for in depth assessment once abuse is disclosed (GAO, 2005). One study found that domestic violence specialists, although not seen by a large percentage of women, were seen as very helpful (Lein et al., 2001). Most women wanted comprehensive case management for a variety of practical problems rather than work rule waivers or referrals to shelters (see Postmus, 2002).

\footnotetext{
4 Wisconsin did not adopt the federal FVO but has other pertinent policies. This state is held as an example of early and successful welfare reform.
}

However, referrals to domestic violence specialists may not occur if caseworkers see that there is no feedback from the specialist to the caseworker on the progress of the case (Levin, 2001). In-depth case studies in seven counties found many of the same results as those above (Burt, Zweig, Schlichter, 2000). Determined leadership and a significant amount of staff training seemed necessary to change the way staff related to clients and to produce an atmosphere that clearly conveyed a sense of dedication to helping clients.

\section{Client Reluctance to Disclose}

There appear to be several major reasons why clients are reluctant to disclose abuse. Clients might fear that their abusers will learn of their disclosure, despite statements about confidentiality. They may also fear losing child custody if a report is made to the child protection unit (Brandwein \& Filiano, 2000; Postmus, 2002). They may not want to talk about traumatic incidents or they may feel ashamed of being a victim (Brandwein, 1999). Only $32 \%$ of the victims in a Wisconsin survey disclosed their abuse to a caseworker. The main reasons for not disclosing abuse were that "it was not the caseworker's business" (32\%) or they felt ashamed (24\%) (Moore \& Selkowe, 1999). Only a small proportion did not disclose because they thought the caseworker would not have time or be sensitive, or that they would lose their benefits. In a Michigan study of battered women on welfare, the major reasons for not talking about abuse were that the worker did not ask and the women had a fear of negative outcomes (Saunders, Holter, Pahl, Tolman, \& Kenna, 2005).

\section{Determinants of Using the Family Violence Option}

A waiver for TANF requirements can be offered after domestic violence is disclosed. Waivers help women by giving them time to attend court hearings, obtain restraining orders, and seek medical and emotional help (Lein et al., 2001). However, the use of waivers is not necessarily an indicator of intervention effectiveness. Some victims do not want or need waivers (Lein et al., 2001). Some states extend time limits at the end rather than give immediate waivers, and some states count receipt of domestic violence services as work time and thus do not require waivers (Burt, Zweig \& Schlichter, 2000; Raphael, 1999). A disadvantage of waiver use is that states do not have to provide social services and needs may go unrecognized. In some instances, waivers are not used because workers do not inform clients that they are an option. For example, only about half of the clients who were receiving domestic violence services in six California counties said that the staff had informed them of the FVO (CIMH, 2000). Having a domestic violence provider in the county increased the use of the FVO and of 
domestic violence services. Many states keep limited information on the number of waivers granted, but in a survey of eight states it appeared that only a small percentage of those disclosing abuse were given waivers (GAO, 2005).

One study suggested that exemptions are likely to be given to the clients in the most danger. Caseworkers were asked to rank order seven case vignettes on the extent to which they would exempt the women in the vignettes from welfare requirements (Hagen \& Owens-Manley, 2002). Priority for an exemption was given to the three women and their children who were in the most immediate danger, and whose situations involved repeated harassment, threats to kill, or child sexual abuse.

\section{Comparisons With Other Professionals}

The responses of welfare workers to domestic violence parallel those of other professionals in many ways. Child protection workers, for example, often do not ask about or detect domestic violence (Magen, Conroy, Hess, Panciera, \& Simon, 1995; Magen \& Conroy, 1997; Shepard \& Raschick, 1999). Only a third of the licensed social workers in diverse settings ask female clients about abuse most or all of the time (Danis, 2003). Other professionals greatly under-detect domestic abuse (e.g., Hamberger, Saunders \& Hovey, 1992) and often get low ratings of helpfulness from victims (see Gordon, 1996). Although social work services are generally rated as more helpful than many other types of service (Hamilton \& Coates, 1993; Horton \& Johnson, 1993), specific work settings, gender differences, theoretical orientations, and stereotypes about battered women seem to outweigh professional background when determining responses toward survivors (Davis, 1984; Harway \& Hansen, 1993; Magen \& Conroy, 1997; Ross \& Glisson, 1991; Saunders \& Anderson, 2000; Saunders, Lynch, Grayson \& Linz, 1987).

\section{Training Effects}

We found only one quantitative study on the effects of training welfare workers about domestic violence (CIMHCalWORKS, 2002c). From 3 to 19 hours of domestic violence training was conducted with welfare eligibility workers and employment counselors in five California counties (the hours varying by county). Most of those trained rated the trainings as "moderately helpful" or "very helpful." The trained workers were much more likely to make referrals for service than untrained workers.

\section{Purpose of Study}

The main purpose of this study was to evaluate a voluntary, one-day training for TANF workers and their supervisors. Another purpose was to determine if responses to case vignettes about domestic violence differed depending on the characteristics of the worker, such as gender, education, and prior knowledge of domestic violence. A final purpose was to understand the characteristics of workers who exempt clients from work requirements. We predicted that: (a) the effects of training would be positive but weak because it was only one day and did not have a follow-up "booster" session or include a standardized screening protocol; (b) training would have a stronger effect on responses to a case with overt signs of abuse than to a case with subtle signs of abuse; and (c) the granting of waivers for work requirements would be related to domestic violence training, prior domestic violence education, and offering other forms of help.

\section{Method}

\section{Training Procedures}

The state's domestic violence training unit conducted the training and encouraged welfare managers and workers to attend a one-day training session aimed at helping them to identify and understand domestic violence, develop safety plans, and make referrals. It specifically covered several key issues: the definition and nature of domestic violence, ways victims try to protect themselves and their children, guidelines for interviewing clients, initial interview questions, identifying domestic violence, lethality indicators, helpful interventions, and safety planning tools. A highly experienced domestic violence specialist conducted 63 trainings at 10 sites throughout the state. The trainings we evaluated with a post-only design were conducted between May 1998 and October 1998. The trainings we evaluated with a pre/post design were conducted between July 2000 and December 2000.

\section{Reactions to Trainings}

One of the authors observed a training and discussed it afterward with some of the participants. They seemed very interested in the topic of domestic violence and their questions revealed that their clients experienced domestic violence-related problems. However, the workers felt that they were too "swamped" to give much individual attention to clients, and thus it was very difficult to screen for domestic violence. They believed that they would be able to spend more time helping clients if they had fewer clients and less paperwork. Some were adjusting to a new role: moving from eligibility functions to case management functions. Their perceptions were supported by two interview studies with caseworkers and managers that highlighted problems during this time period, including excessive paperwork, role transitions, computer system problems, retirement of many of the most experienced staff, "too many trainings," and new requirements to conduct home visits (Seefeldt, Danziger, \& Anderson, 1999; Seefeldt \& Peters, 2000). 


\begin{tabular}{|c|c|c|c|c|c|c|}
\hline \multirow[b]{3}{*}{ ITEMS } & \multicolumn{2}{|c|}{ POST ONLY } & \multirow[b]{3}{*}{$t$ VALUE } & \multirow{3}{*}{$\begin{array}{c}\text { PRE } \\
n=36\end{array}$} & \multirow{3}{*}{$\begin{array}{c}\text { POST } \\
n=36\end{array}$} & \multirow[b]{3}{*}{$t$ Value } \\
\hline & UNTRAINED & TRAINED & & & & \\
\hline & $n=47$ & $n=192$ & & & & \\
\hline Assessment items $(1-3,8)$ & 59.9 & 59.5 & 0.1 & & & \\
\hline 1. Ask about abusive behaviors & 68.4 & 64.6 & 0.7 & 70.1 & 78.5 & 1.4 \\
\hline 2. Ask about impact: emotional \& phys. & 72.4 & 69.2 & 0.6 & 75.8 & 83.6 & $2.1^{*}$ \\
\hline 3. Ask how disagreements handled & 50.2 & 49.2 & 0.2 & 63.1 & 68.0 & 0.7 \\
\hline 4. Refer to couples counseling & 33.7 & 47.4 & $-2.3^{* *}$ & 62.2 & 49.2 & $-1.7^{*}$ \\
\hline 5. Create safety plan & 62.4 & 73.5 & $-1.9 *$ & 57.0 & 77.5 & $2.6^{* *}$ \\
\hline 6. Refer to legal advocate & 67.7 & 70.1 & -0.4 & 68.9 & 74.3 & 1.0 \\
\hline 7. "How can you stay ...hurting children?" & 40.6 & 46.9 & -1.0 & 43.3 & 40.0 & -0.6 \\
\hline 8. Ask about access to weapons & 48.7 & 51.7 & -0.5 & 50.8 & 72.9 & $3.3^{* * *}$ \\
\hline 9. File report: Child Protection Services & 69.7 & 80.4 & $-1.8^{*}$ & 78.7 & 82.9 & 0.9 \\
\hline $10 . \%$ clients battered women, past 6 mos. & 23.0 & 23.1 & 0.0 & 23.8 & 22.1 & -0.4 \\
\hline $11 . \%$ battered women referred, past 6 mos. & 49.1 & 49.7 & -0.1 & 40.1 & 35.6 & 0.9 \\
\hline $12 . \%$ battered women exempted from work & 46.7 & 42.3 & 0.6 & - & - & - \\
\hline
\end{tabular}

Note: Items 1-9 are responses to vignettes with domestic violence. Items 10-12 are actual reports. Standard deviations can be sent upon request.

${ }^{*} p<.05 .{ }^{* *} p<.01 .{ }^{* * *} p<.001$, one-tailed.

\section{Measures}

We constructed two vignettes for the study: one with obvious content about domestic violence ("Jean"; see Appendix) and one with domestic violence risk markers but no mention of domestic violence ("Marie"; see Appendix). Including this second vignette helped with our assessment of the ability to detect abuse. Participants indicated the likelihood, from $0 \%$ to $100 \%$, of their making various responses if they were interviewing the hypothetical client. We derived the items from the goals of the training, as well as current policy concerns. The trainer reviewed them to ensure that they covered the goals of the training. In the obvious vignette, nine response options covered assessment of abuse, risk factors for abuse, referrals, safety planning, and inducing guilt for staying in the relationship (see Table 1). Items also asked about referrals and work exemptions made for actual clients in the past six months: "In the last six months, what percent of your clients who were battered women did you exempt from work requirements?" and "In the last six months, what percent of your clients who were battered women did you refer for domestic violence-related services (e.g., legal, police, specialized counseling, shelter)?"

We conducted a principal component factor analysis with varimax rotation in an attempt to reduce the number of items. It revealed two factors. A set of four assessment items formed a reliable subscale, called "Assessment," with an internal reliability coefficient (alpha) of .84 . These items $(1,2,3 \& 8)$ reflected inquiries about abusive behaviors, impact of the violence, how disagreements were handled, and access to weapons. A second factor did not form a reliable subscale. Both the Assessment Subscale and individual items were used in the analysis.

For the vignette without obvious content, possible responses to the vignette client included empathy, asking about abuse, emotional and physical well-being, how conflict is handled, jealousy of partner, fear of partner, enforced isolation, and why she is in the relationship. Factor analysis revealed a single factor and therefore responses were analyzed individually.

\section{Evaluation Design and Sampling Procedures}

Design. We used two types of evaluation designs: postonly and pre-post. The post-only evaluation was conducted because almost all of the trainings had occurred after the evaluation process began. We compared trainees and non-trainees on their responses to one of the two vignettes mailed to them after the trainings. Respondents returned questionnaires between September 1999 and June 2000. One advantage of post-only evaluations is that responses after the training are not influenced by exposure to the instrument at pre-testing. On the other hand, there is no comparison with pre-training levels. Fortunately, the domestic violence training unit conducted more trainings and we were able to have a small sample with pre- and post-training measures. These trainees responded only to the version of the vignette with obvious domestic violence content. In this case they completed the pre-questionnaire immediately before the training and the post-questionnaire two to three to six months afterwards.

Sampling of counties. We recruited workers for the study from counties selected for varying levels of trainee participation, demographic characteristics, and regions of the state. Differing levels of trainee participation (from a low of $43 \%$ to a high of $100 \%$ per county) could reflect the attitudes of managers and caseworkers. We over-sampled untrained workers in counties with high levels of participation in training. We also included counties that were predominantly urban or rural, relatively wealthy or poor, and relatively high or low in rate of the proportion of Caucasians. The final 
TABLE 2. Comparison of Caseworkers Least and Most Likely to Exempt Survivors from Work Requirements

\begin{tabular}{|c|c|c|c|c|c|}
\hline \multirow[b]{2}{*}{ VIGNETTE ITEMS } & \multicolumn{2}{|c|}{ LEAST LIKELY TO EXEMPT $(n=141)$} & \multicolumn{2}{|c|}{ MOST LIKELY TO EXEMPT $(n=43)$} & \multirow[b]{2}{*}{$t$ VALUE } \\
\hline & $\begin{array}{l}\text { AVERAGE } \\
\text { LIKELIHOOODa }\end{array}$ & $\begin{array}{l}\text { STANDARD } \\
\text { DEVIATION }\end{array}$ & $\begin{array}{l}\text { AVERAGE } \\
\text { LIKELIHOOD }\end{array}$ & $\begin{array}{l}\text { STANDARD } \\
\text { DEVIATION }\end{array}$ & \\
\hline Assessment Items $(1-3,8)$ & 57.3 & $(29.4)$ & 63.7 & $(26.7)$ & $-1.71 *$ \\
\hline Couples counseling & 40.1 & $(37.1)$ & 49.4 & $(35.3)$ & $-1.79 *$ \\
\hline Safety planning & 69.1 & $(36.0)$ & 73.8 & $(30.9)$ & -1.10 \\
\hline Referral to legal advocate & 65.1 & (34.5) & 76.1 & $(29.6)$ & $-2.60 * *$ \\
\hline Says staying hurts children & 47.7 & $(40.1)$ & 42.6 & $(38.8)$ & 1.00 \\
\hline Report to CPS & 79.6 & $(32.4)$ & 77.6 & $(30.4)$ & -0.90 \\
\hline Other Items & AVERAGE & SD & AVERAGE & SD & $t$ VALUE \\
\hline Average $\%$ of battered women clients & 18.7 & $(13.5)$ & 29.7 & $(19.3)$ & $-4.80 * * *$ \\
\hline Average $\%$ of battered women referred & 28.5 & $(32.3)$ & 81.7 & $(29.8)$ & $-12.80 * * *$ \\
\hline Education level & 02.7 & $(01.1)$ & 02.7 & $(01.3)$ & -0.30 \\
\hline Prior domestic violence information & 22.3 & $(40.1)$ & 27.6 & $(42.3)$ & -0.90 \\
\hline Years work experience & 16.7 & (08.8) & 16.6 & $(07.7)$ & 0.80 \\
\hline
\end{tabular}

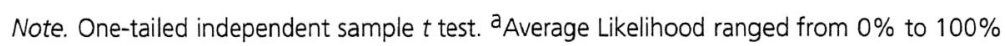

${ }^{\star} p<.05 .{ }^{* \star} p<.01 .{ }^{* * *} p<.001$.

sample consisted of 15 counties. We did not evaluate the training in the most populous county (Wayne County), which includes Detroit, because it was used for pilot trainings and they used their own domestic violence trainers.

The counties included in the analysis ranged in population from approximately 30,000 to over 1 million. Four of the counties had populations of less than 100,000. Median household income ranged from $\$ 25,237$ to 59,677 , with 10 of the 15 counties recording median incomes higher than that of Michigan as a whole ( $\$ 38,800$ median income). The percentage of the population with incomes below the poverty rate ranged widely, from $4.9 \%$ to $17 \%$. The percentage of children living in poverty ranged from $6.3 \%$ to $28.6 \%$. The percentage of Caucasians in the county population varied somewhat, with the highest being $98 \%$ in one county, and the lowest being $75 \%$ in another county. The number of persons in each county receiving welfare benefits ranged from 1.3 to 18.8 per thousand.

Participants. There were 2,150 Family Independence Specialists and Family Independence Managers in the state at the time of the training, excluding Wayne County; 1,889 workers attended one of the initial trainings we evaluated. After the training, we sent surveys to 932 trained and untrained managers and workers in the 15 counties. The overall response rate was $52 \% .{ }^{5}$ Of those responding to the vignette with obvious abuse ("Jean"; $n=243$ ), $21 \%$ were men and $79 \%$ were women; they averaged $16.6(S D=8.3)$ years of experience in the social services; and they had the following educational experience: $14.5 \%$ high school; $29.0 \%$ some college; $40.1 \%$ college degree; $5.0 \%$ one year graduate school; $8.3 \%$ two years graduate school; $2.5 \%$

5 Four hundred eighty-two (52\%) responded to one of four vignettes. Versions of
the vignettes with open-ended response formats were discontinued after the
first wave of mailings due to low response rates ( $11 \%$ of returns of all versions). postgraduate studies. Sixty percent had read at least one article about domestic violence; $37 \%$ had read at least one book, and $20 \%$ had received at least one consultation on domestic violence.

Of those responding to the vignette without obvious abuse ("Marie"; $n=117$ ), $25 \%$ were men and $75 \%$ were women. They averaged $16.7(S D=7.5)$ years of social service experience, and had the following educational experience: $10.2 \%$ high school; $36.4 \%$ some college; $42.8 \%$ college degree; $5.3 \%$ one year graduate school; $5.3 \%$ two years graduate school; $0.0 \%$ postgraduate studies.

In the pre-post evaluation, we administered questionnaires with the obvious content about domestic violence to 118 workers immediately before and three to six months after the training, with 67 workers having complete pre-post data.

\section{Results}

\section{General Responses}

Across both of the samples and regardless of training status, the items on the overt domestic violence vignette (Jean) with the highest reported likelihood were: (a) asking about abusive behaviors, (b) asking about the emotional and physical impact of abuse, and (c) referring for legal advocacy. Items with the lowest reported likelihood were: (a) referring for couples counseling (34-49\% response probability) and (b) asking, "how can you stay in a situation that is hurting your children so much?" (40-47\% response probability). Workers estimated that $23 \%$ of their clients in the past six months were battered women. They reportedly gave work exemptions to about half of these women and referred $35-50 \%$ for other services.

The items with the highest reported likelihood on the "subtle" vignette (Marie), regardless of training (all over $70 \%$ average likelihood), were: (a) asking about emotional 
TABLE 3. Hierarchical Regression Predicting Use of Work Exemption in Past 6 Months

\begin{tabular}{|c|c|c|c|c|c|}
\hline PREDICTOR & $r$ & SteP 1 & SteP 2 & Step 3 & Step 4 \\
\hline Gender & .04 & .04 & .06 & .06 & .06 \\
\hline Years work experience & -.07 & -.06 & -.06 & -.05 & -.03 \\
\hline Educational level & .04 & .04 & .03 & .03 & .00 \\
\hline Prior inform. on dom. viol. & .06 & .06 & .05 & .05 & .03 \\
\hline Assessment for dom. viol. & .09 & & .08 & .07 & -.01 \\
\hline Couples counseling referral & $.12^{*}$ & & .09 & .10 & .08 \\
\hline Safety planning & .03 & & -.09 & -.08 & $-.13^{*}$ \\
\hline Legal advocacy & $.14^{*}$ & & $.13^{*}$ & $.13^{\star}$ & .01 \\
\hline Says staying hurts child & -.03 & & -.05 & -.05 & -.05 \\
\hline Make CPS report & -.03 & & -.08 & -.08 & -.05 \\
\hline Training & -.06 & & & -.05 & -.05 \\
\hline No. of battered women clients & $.26^{\star \star *}$ & & & & .07 \\
\hline Referral of battered women & $.62 * * *$ & & & & $.61^{* \star *}$ \\
\hline$R^{2}$ & & .01 & .05 & .05 & $41^{* \star *}$ \\
\hline Change in $R^{2}$ & & .01 & .04 & .00 & $.37 * * *$ \\
\hline
\end{tabular}

Note. $r=$ Bivariate correlation coefficient; standardized regression coefficients are shown in Steps 1 through 4

${ }^{*} p<.05 .{ }^{* *} p<.01 .{ }^{* * *} p<.001$.

and physical well-being, (b) asking about the level of control in her life, and (c) asking if she was ever afraid. Items with the lowest reported likelihood were: (a) asking why she was in the relationship (58-61\% average likelihood) and (b) asking if her partner was extremely jealous (55$59 \%$ average likelihood).

\section{Gender Effects}

There was only one gender difference on the post-only evaluation with the domestic violence vignette: Female workers said they would be more likely to develop a safety plan than male workers ( $73 \%$ average likelihood vs. $60 \%$ average likelihood). There were no gender differences on the "subtle" vignette.

\section{Training Effects}

Table 1 shows the results comparing trained and untrained workers using the domestic violence vignette and actual responses. In the post-only analysis using an independent sample $t$ test, trained workers reported a greater likelihood of referring clients to couples counseling, developing a safety plan, and reporting to child protection services (CPS). The findings on safety planning and CPS reporting are only suggestive given the number of $t$ tests conducted and the low p value. Moreover, the difference on the safety planning item was not significant after controlling for gender, educational level, years of experience in social services, and prior information obtained about domestic violence. The difference on CPS reporting did not hold after controlling for years of experience. ${ }^{6}$ There were no significant differences on any of the other items.

We asked another sample of workers in the pre-post design to rate their responses to the same vignette in several

\footnotetext{
6 Another Analysis of Covariance was conducted with three outliers removed and the results were the same as the original Analysis of Covariance.
}

areas before and after the training (see Table 1). Workers reported significant improvement after training in asking about the impact of emotional and physical abuse, helping the woman with a safety plan, and asking about access to weapons. Workers reported that they were less likely to refer clients to couples counseling after the training. In response to the vignette with no direct reference to domestic violence, trained and untrained workers did not differ. Controlling for background variables did not change these results.

\section{Work Exemptions}

Workers reported that, in the six months prior to participating in this study, they had tended to give exemptions to battered women either all of the time or not at all: $50 \%$ said "never" or "almost never" and 25\% said "always." For our first analysis, workers were divided into these two extreme groups: most likely ("always") and least likely to exempt ("never" or "almost never"). Table 2 shows the differences between these groups. The most likely to exempt group was significantly higher on the following vignette responses: assessment, referral to couples counseling, and referral to a legal advocate. Their responses indicate that they were more likely to have clients who were battered in the past six months and that they were more likely to refer these clients for domestic violencerelated services. This latter finding was the strongest. Those most likely to exempt referred an average of $82 \%$ of their clients, compared with only $28 \%$ making referrals in the low exempting group.

The above findings remained after conducting a multiple regression analysis controlling for gender, background, vignette responses and number of battered women clients (see Table 3). The tendency to refer for legal advocacy was significantly related to use of work exemptions when controlling for other variables, except when actual referrals were added to the equation in the last step. The legal 
advocacy and safety planning variable coefficients changed dramatically at this step due to suppression effects from high correlations among the independent variables. Men and women and trained and untrained workers did not differ in the percentage of cases with work exemptions granted, in either bivariate or multivariate analyses.

\section{Discussion}

In the post-only comparison of trained and untrained workers, there were only three significant differences. Trained workers reported a greater tendency to refer to couples counseling, make a safety plan, and file a report with child protection services. However, the latter two findings did not hold after controlling for demographic and background variables.

In the pre-post analysis, four of the nine comparisons were significant. After training, workers reported that they would be more likely to ask about the emotional and physical impact of abuse, make a safety plan, and ask about access to weapons. They reported a decreasing tendency to refer for couples counseling after training. However, the average likelihood of a couples counseling referral from both trained groups was just under $50 \%$, a concern discussed later in this report. The somewhat better outcomes for the pre-post sample could be explained by possible improvement in training methods or increased policy diffusion over time, since these groups were conducted after the post-only groups. With the exception of a tendency to refer couples to counseling, in general, the effects of training were positive, but weak, as expected.

As expected, trained and untrained workers did not differ on responses to the vignette without obvious references to domestic abuse. This finding indicates that trained workers were not being guided by risk factors for abuse. The relatively high reported likelihood that both trained and untrained workers would ask about abuse, the woman's fear level, and the level of control in her life provides reassurance about caseworkers' responses.

As predicted, workers who were most likely to offer a work exemption or a waiver from work requirements were also the workers reporting a higher likelihood of assessing for domestic violence, and referring for couples counseling and legal advocacy in response to the vignette. They were also the ones more likely to actually refer battered women for services. These findings remained after controlling for demographic, background and other variables.

The tendency for both trained and untrained workers to refer clients to couples counseling raises a concern that battered women could be endangered further. Traditionally-oriented couples counselors tend to minimize the danger in domestic violence cases (Harway \& Hansen, 1993). As in one analysis of the tendency among Michigan child protection workers to give couples counseling referrals (Saunders \& Anderson, 2000), these TANF workers appear to be recommending all avenues of help to clients. Future trainings may need to provide more caveats about couples counseling. The reports from survivors about couples counseling referrals in these same counties were reassuring, as only $9 \%$ reported such referrals (Saunders, Holter, Pahl, Tolman, \& Kenna, 2005).

Several weaknesses in the evaluation methods we used reduce the strength of the above conclusions. First, the sample was comprised of those who voluntarily attended the trainings, and results might be different if all the workers had been trained. Second, the measures were developed for the study and we conducted only one test of reliability. Third, we used a non-experimental design, and thus any of the differences between trained and untrained groups could be attributed to factors other than the training.

Future evaluations can arrive at firmer conclusions using experimental designs and can assess additional training features, such as longer trainings and booster sessions (Ganow, 2001). More experiential training methods or other changes in the training might also have produced more significant results (see Davies, 2000, for detailed training recommendations). A brief screening instrument to help guide the task of identification and to help workers feel more comfortable talking about abuse might be especially useful. Such screening instruments in child protection worker training has led to increased detection rates (Magen \& Conroy, 1997). Domestic violence screening instruments of two to four questions for use by TANF workers or advocates in TANF offices have been implemented in some states (Burt, Zweig, \& Schlichter, 2000; Ganow, 2001). Experience in other states indicates that thorough training in the use of screening instruments is necessary and that procedures for protecting confidentiality must be in place (ASPE, 1997; Burt, Zweig, \& Schlichter, 2000; Davies, 1998b; Ganow, 2001; Lyon, 2002). As noted earlier, there is some empirical support for the use of direct questioning for screening, rather than indirect methods like brochures. The U.S. General Accounting Office recommended recently that the U.S. Department of Health and Human Services provide states with the most promising screening practices and encourages their adoption (GAO, 2005).

Assessment methods that are more extensive than screening may be needed. Some programs focus on the many forms of violence women experience, how their lives are affected by it, and specific barriers to finding safety (ASPE, 1997). In addition empirical support exists for intensive case management and for making available a domestic violence specialist-either a local program advocate, or an in-house specialist. Such specialists may be needed to conduct thorough assessments. A culture change in each agency may ultimately be necessary to further women's and children's safety while helping women to become more economically independent (Burt, Zweig, \& Schlichter, 2000). Such a comprehensive change could increase the agency's overall "climate of helpfulness," staff 
training, and assessment of barriers to independence. Rather than fear of sanctions, positive incentives and supports are most likely to assist women toward independence and increased safety for themselves and their children (Burt, Zweig, Schlichter, 2000).

\section{References}

Administration for Children and Families (AFC), Office of Family Assistance (2002). Temporary Assistance for Needy Families (TANF). Fifth Annual Report to Congress. Retrieved May 21, 2003 from http://www.acf.dhhs.gov/programs/ofa/annualreport5/1212.htm.

Anderson, D. K., \& Saunders, D.G. (2003). Leaving an abusive partner: An empirical review of predictors, the process of leaving, and psychological well-being. Trauma, Violence, and Abuse, 4, 163-191.

Assistant Secretary for Planning and Evaluation (ASPE). (1997). Ancillary services to support welfare to work: Domestic violence. U.S. HHS Assistant Secretary for Planning Evaluation. Retrieved July 4, 2002 from http://aspe.hhs.gov/hsp/isp/ancillary/DV/htm.

Brandwein, R. A. (1999). Family violence and welfare use: Report from the field. In R. A. Brandwein (Ed.) Battered women, children, and welfare reform (pp. 45-58). Thousand Oaks, CA: Sage Publications.

Brandwein, R. A., \& Filiano, D. M. (2000). Toward real welfare reform: The voices of battered women. Affilia, 15(2), 224-243.

Brush, L. D. (1999). Women battering and welfare reform: The view from a welfare-to-work program. Journal of Sociology \& Social Welfare, 26(3), 49-60.

Brush, L.D. (2000). Battering, traumatic stress, and welfare-to-work transition. Violence Against Women, 6(10), 1039-1065.

Brush, L. D. (2003). Effects of work on hitting and hurting. Violence Against Women, 9(10), 1213-1230.

Burt, M. R., Zweig, J. M., \& Schlichter, K. (2000). Strategies for addressing the needs of domestic violence victims within the TANF program: The experience of seven counties: Final Report. U.S. Department of Health and Human Services, Office of the Assistant Secretary for Planning and Evaluation HHS-100-95-0021.

CIMH-CalWORKS. (2000). The CalWORKS Project: Six County Case Study-Alameda, Kern, Los Angeles, Monterey, Shasta, Stanislaus: Executive Summary. Sacramento, CA: California Institute for Mental Health.

CIMH-CalWORKS. (2002a). Impact of alcohol and other drugs, mental health problems and domestic violence on employment and welfare tenure. CIMH: CalWORKS Project, Policy and Practice Brief, 2.

CIMH-CalWORKS. (2002b). Mental health, domestic violence and substance abuse: Need for and use of services among adult female TANF participants. CIMH: CalWORKS Project, Policy and Practice Brief, 1 .

CIMH-CalWORKS (2002c). The CalWORKS project: Domestic Violence Summary. Sacramento, CA: California Institute for Mental Health.

Coeling, H. V. \& Harman, G. (1997). Learning to ask about domestic violence. Women's Health Issues, 7(4), 263-268.

Danis, F. S. (2003). Social work response to domestic violence: Encouraging news from a new look. Affilia, 18(2), 177-191.

Davies, J. (1996). New welfare law: State implementation and use of the Family Violence Option. Retrieved June 3, 2002 from http://www.vaw.umn.edu/documents/welpol2/welpol2.html.

Davies, J. (1998a). Building Opportunities For Battered Women's Safety And Self-Sufficiency. Welfare and Domestic Violence Technical Assistance Initiative, National Resource Center/ Pennsylvania Coalition Against Domestic Violence.

Davies, J. (1998b). Family Violence Protocol Development. Welfare and Domestic Violence Technical Assistance Initiative, National Resource Center/ Pennsylvania Coalition Against Domestic Violence.
Davies, J. (2000). Recommendations for training TANF and child support enforcement staff about domestic violence. Harrisburg, PA: National Resource Center on Domestic Violence. Retrieved March 15, 2002 from http:// www.vawnet.org.

Davis, L.V. (1984). Beliefs of service providers about abused women and abusing men. Social Work, 29, 243-250.

Davis, L. V., \& Carlson, B. E. (1981). Attitudes of service providers toward domestic violence. Social Work Research \& Abstracts, 17(4), 34-39.

Ganow, M. (2001) Strategies for TANF agencies to identify and address domestic violence. Welfare Information Network: Issue Notes, 5(13). Retrieved March 8, 2002 from http://www.welfareinfo.org.

General Accounting Office (GAO). (1998, November). Domestic violence: Prevalence and implications for employment among welfare recipients. United States General Accounting Office: Report to Congressional Committees.

General Accounting Office (GAO). (2005, August). TANF: State Approaches to screening for domestic violence could benefit from $H H S$ Guidance. United States General Accounting Office: Report to Congressional Requesters.

Gennetian, L. A. (2003). Welfare policies and domestic abuse among single mothers - experimental evidence from Minnesota. Violence Against Women, 9(10), 1171-1190.

Gordon, J. S. (1996). Community services for abused women: A review of perceived usefulness and efficacy. Journal of Family Violence, 11(4), 315-329.

Griswold, E.A., Pearson, J., Thoennes, N. (2000). New directions for child support agencies when domestic violence is an issue. Policy and Practice for Public Human Services, 58, 29-36.

Hagen, J. L., \& Owens-Manley, J. (2002). Issues in implementing TANF in New York: The perspective of frontline workers. Social Work, $47(2)$, 171-182.

Hamberger, L. K., Saunders, D. G., \& Hovey, M. (1992). Prevalence of domestic violence in community practice and rate of physician inquiry. Family Medicine, 24, 256-260.

Hamilton, B., \& Coates, J. (1993). Perceived helpfulness and use of professional services by abused women. Journal of Family Violence, 8(4), 313-323.

Harway, M. \& Hansen, M. (1993). Therapist perceptions of family therapy. In M.Harway and M. Hansen (Eds.) Battering and family therapy: A feminist perspective. Newbury Park, CA: Sage Publications.

Hearn, M. E. (2000). Dangerous indifference: New York City's failure to implement the Family Violence Option. New York City: Joint Project of NOW Legal Defense and Education Fund; The Legal Aid Society; The Women, Welfare, and Abuse Task Force; and The Urban Justice Center.

Horton, A., \& Johnson, B. (1993). Profile and strategies of women who have ended abuse. Families in Society, 74(8), 481-492.

Legal Momentum. (2004). Family violence option: State by state summary [Brochure]. New York: Legal Momentum.

Lein, L., Jacquet, S., Lewis, C. M., Cole, P. R., \& Williams, B. B. (2001). With the best intentions. Violence Against Women, 7(2), 193-210.

Levin, R. (2001). Less than ideal: The reality of implementing welfare-towork programs for domestic violence victims. Violence Against Women, 7(2), 211-221.

Lindhorst, T., \& Padgett, J. D. (2005). Disjunctures for women and frontline workers: Implementation of the family violence option. Social Service Review, 79(3), 405-429.

Lyon, E. (2002). Welfare and domestic violence against women: Lessons from research. Retrieved November 15, 2001. VAWnet: National Resource Center on Domestic Violence and Penn. Coalition Against Domestic Violence.

Magen, R. H., \& Conroy, K. (1997, June). Domestic violence in child welfare preventative services: Results from an intake screening questionnaire. Paper presented at the 5th International Family Violence Research Conference, University of New Hampshire, NH. 
Magen, R. H., Conroy, K., Hess, P. M., Panciera, A., \& Simon, B. L. (1995, July). Evaluation of a protocol to identify battered women during investigations of child abuse and neglect. Paper presented at the 4th International Family Violence Research Conference, University of New Hampshire, NH.

McKean, L. (2004). Self-sufficiency and safety: The case for onsite domestic violence services at employment services agencies. Unpublished report, Center for Impact Research, Chicago, IL.

Meisel, J., Chandler, D., \& Rienzi, B. M. (2003). Domestic violence prevalence and effects on employment in two California TANF populations. Violence Against Women, 9(10), 1191-1212.

Moore, T., \& Selkowe, V. (1999, September). Domestic violence victims in transition from welfare to work: Barriers to self-sufficiency and the W-2 response. The Institute for Wisconsin's Future.

Pearson, J., Griswold, E. A., \& Thoennes, N. (2001). Balancing safety and self-sufficiency: Lessons on serving victims of domestic violence for child support and public assistance agencies. Violence Against Women, 7(2), 176-192.

Postmus, J. L. (2002). In their own words: Battered women, welfare, and the Family Violence Option. Dissertation Abstracts International, A 63/05. (UMI No. 3053353)

Raphael, J. (1999). The family violence option: An early assessment. Violence Against Women, 5(4), 449-466.

Raphael, J. (2000). Saving Bernice: Battered women, welfare, and poverty. Boston: Northeastern University Press.

Raphael, J., \& Haennicke, S. (1999). Keeping battered women safe through the welfare-to-work journey: How are we doing? Chicago, IL: Taylor Institute.

Rhodes, N. R., \& McKenzie, E. B. (1998). Why do battered women stay? Three decades of research. Aggression and Violent Behavior, 3, 391-406.

Romero, D., Chavkin, W., Wise, P. H., \& Smith, L. A. (2003). Low-income mothers' experience with poor health, hardship, work, and violence-Implications for policy. Violence Against Women, 9(10), 1231-1244.

Rossman \& Associates (1999, October). Family Independence Agency Image Project: Research Results, Conclusions, Analysis, and Recommendations. Lansing MI: Rossman, Martin \& Associates.

Ross, M., \& Glisson, C. (1991). Bias in social work intervention with battered women. Journal of Social Service Review, 14, 79-105.

Sable, M. R., Libbus, M. K., Huneke, D., \& Anger, K. (1999). Domestic violence among AFDC recipients: Implications for welfare-to-work programs. Affilia, 14(2), 199-216.

Sachs, H. (2000). Domestic violence as a barrier to women's economic self-sufficiency. Welfare Information Network, 3(10).

Saunders, D. G., \& Anderson, D. (2000). Evaluation of a domestic violence training for child protection workers \& supervisors: Initial results. Children and Youth Services Review, 22(5), 373-395.

Saunders, D. G., Lynch, A. B., Grayson, M., \& Linz, D. (1987). The inventory of beliefs about wife-beating: The construction and initial validation of a measure of beliefs and attitudes. Violence and Victims, 2, 39-58.

Saunders, D.G., Holter, C., Pahl, C., \& Tolman, M. (2005). TANF workers' responses to battered women and the impact of brief worker training: What survivors report. Violence Against Women, $11,227-254$.

Saunders, T., Ward, J., \& Dow, M. (1999). Evaluation of Work First Plus Program: Six Month Report. Tampa, FL, University of South Florida, Louis de la Parte Florida Mental Health Institute.

Seefeldt, K.S., Danziger, S.K., \& Anderson, N. (1999). What FIA directors have to say about welfare reform. University of Michigan, Program on Poverty and Social Welfare Policy.

Seefeldt, K.S. \& Peters, J. (2000). The Family Independence Specialist: Successes and challenges. University of Michigan, Program on Poverty and Social Welfare Policy.

Shepard, M., \& Raschick, M. (1999). How child welfare workers assess and intervene around issues of domestic violence. Child Maltreatment, 4(2), 148-156.

Staggs, S. L., \& Riger, S. (2005). Effects of intimate partner violence on low-income women's health and employment. American Journal of Community Psychology, 36(1-2), 133-145.
State of Michigan, Act 162, Public Acts of 1997, House Bill No. 4811, MCL 400.1 to $400.119 \mathrm{~b}$, adding section 561 .

Sugg, N. K. \& Inui, T. (1992). Primary care physicians' response to domestic violence: Opening Pandora's box. JAMA, 267, 3157-60.

Swanberg, J. E., \& Logan, T. K. (2005). Domestic violence and employment: A qualitative study. Journal of Occupational Health Psychology, 10(1), 3-17.

Tolman, R. M. \& Raphael, J. (2000). A review of research on domestic violence and welfare. Journal of Social Issues, 56(4), 655-682.

Tolman, R. M. \& Rosen, D. (2001). Domestic violence in the lives of women receiving welfare: Health, mental health and well-being. Violence Against Women, 7(2), 126-140.

APPENDIX

Vignette 1: "Jean"

A client of yours, Jean, is receiving TANF benefits. She has three children, ages 2, 4, and 13 . She has not been showing up for required job-training classes and could lose her benefits as a result. She comes to your office and tells you:

I haven't been able to go to classes because of problems at home. My boyfriend got mad and beat me up again. The kids were there and saw it. He's never hit the kids on purpose, but my oldest boy tried to stop the fighting and got in the middle of it. Now my kids won't go to a sitter because they worry about me. They won't let me leave their sight without screaming and crying. I can't lose my benefits because I have no other money for food and clothes.

She explains that although her boyfriend is unemployed she does not trust him to babysit.

\section{Vignette 2: "Marie"}

Marie comes into your agency to see if her family can qualify to receive TANF. As you begin asking her questions about her income you learn the following: She has two children ages 2 and 4 residing in the house with her. Marie's boyfriend, Jake, sometimes stays with them. Jake is employed as a custodian and when he's around he gives Marie $\$ 40$ a week to buy groceries for the family. Marie doesn't work because "Jake doesn't want me to spend time with anyone but him."

Marie was once accepted for a position at a local gas station, but when Jake found out, "he called me a good-for-nothing whore who's too stupid to even pump gas." Marie hasn't tried to find employment since then for fear of what Jake might say.

Daniel G. Saunders, $\mathrm{PhD}$, is professor, School of Social Work, University of Michigan, 1080 S. University Ave., Ann Arbor, MI 48109-1106. Mark Holter, $\mathrm{PhD}$, is associate professor, School of Social Welfare, University of Kansas. Lisa Pahl, MSW, is a licensed clinical social worker at Vitas Healthcare Corporation, Torrance, CA. Richard Tolman, $\mathrm{PhD}$, is professor, School of Social Work, University of Michigan. Correspondence regarding this article may be sent to the first author at the address above or saunddan@umich.edu.

Authors' note. The authors are grateful to the Michigan Family Independence Agency and the University of Michigan Provost Interpersonal Violence Fund for funding the project; to Debra Cain, Joyce Wright, Sarah Heuser, and Penny Hackett-Evans for their advice on measures, comments on the document, and assistance with response ratings; to Anna Melbin, Colleen Kenna, and Jody Raphael for their comments on the document; and to Claire Kotwick, Juhee Kim, and Madhu Penubarthi for their assistance with data entry and data management. The views and conclusions expressed in this report are not necessarily those of the Michigan Domestic Violence Prevention and Treatment Board or the Michigan Department of Human Services.

Manuscript received: August 2, 2004

Revised: October 14, 2004

Accepted: October 15, 2004 